\title{
BIBLIOTECA SAUSSURIANA À LA BORGES: UM CONVITE
}

Maria Iraci Sousa Costa

http://orcid.org/0000-0002-5551-4557

Caroline Mallmann Schneiders**

(iD) https://orcid.org/0000-0003-4365-8737

Amanda Eloina Scherer***

(iD) http://orcid.org/0000-0002-7183-805X

Como citar este artigo: COSTA, M. I. S.; SCHNEIDERS, C. M.; SCHERER, A. E. Biblioteca saussuriana à la Borges: um convite. Todas as Letras - Revista de Lingua e Literatura, São Paulo, v. 22, n. 2, p. 1-23, maio/ago. 2020. DOI 10.5935/19806914/eLETDO2013438

Submissão: maio de 2020. Aceite: julho de 2020.

Resumo: Refletir sobre a obra de Ferdinand de Saussure implica reportarmo-nos à problemática das noções de corpus e arquivo naquilo que toca o conjunto heterogêneo de publicações que foram publicadas por Saussure e atribuídas a ele. Partindo dessa problemática e inspiradas em um conto de Borges, "A Biblioteca de Babel", no presente artigo, buscamos propor uma reflexão a respeito da permanência do Curso de Linguística Geral e de sua inconstância, bem como sobre a sua capacidade de ser reinventado e manter-se na ordem do dia por mais de um século. Refletiremos também sobre o árduo trabalho dos pesquisadores que têm se dedicado ao estudo desse complexo conjunto heterogêneo de textos que se atribui a Saussure. À moda de uma biblioteca (de Babel à la

\footnotetext{
* Universidade Federal de Pelotas (UFPel), Pelotas, RS, Brasil. E-mail: iraciscosta@yahoo.com.br

** Universidade Federal da Fronteira do Sul (UFFS), Cerro Largo, RS, Brasil. E-mail: carolletras2005@yahoo.com.br

*** Universidade Federal de Santa Maria (UFSM), Santa Maria, RS, Brasil. E-mail: amanda.scherer@gmail.com
} 
Borges), organizamos nosso texto por estantes (de galerias hexagonais) para procurar compreender a vastidão e a complexidade do conjunto de obras e documentos que se atribui a Saussure.

Palavras-chave: História. Memória. Corpus. Arquivo. Manuscritos.

\section{Preliminarmente é Preciso dizer}

"O homem de ciência trabalha com ficções racionais que
tornam o seu discurso possível" (AUROUX, 2008, p. 156).

P ara nós, não existe produção do conhecimento sem uma vontade expressa do pesquisador. Essa vontade também se dá pelo interesse em fatos e dados que vão se apresentando (e se acumulando) ao longo da vida acadêmica, desde a graduação, quando decidimos por nossa formação profissional, até a nossa formação como pesquisador e nosso exercício enquanto tal. Vamos a Letras porque gostamos das letras e das Letras em seu sentido fundador e, a nosso ver, inseparáveis: a língua e a literatura. Embora com a invenção do disciplinar e com a manualização do conhecimento linguístico - de todo jeito e a toda prova -, a língua e a literatura acabaram sendo apartadas da sua rede de significações e, desse modo, a divisão social (e acadêmica) acabou criando um fosso entre elas, separando inclusive os sujeitos e seus objetos (seriam linguas diferentes - lingua e literatura?). Maior exemplo de tal divisão é o que nomeamos na contemporaneidade como área de conhecimento.

Nosso interesse, aqui, não é trazer à tona tal divisão, muito menos o político que a ordena, mas mostrar o quanto somos interpelados pela nossa formação (e, por que não, por essa divisão?) ao nos depararmos com nosso interesse pela linguagem. Desde cedo, quando ainda na graduação, qualquer uma das autoras deste artigo sempre esteve em um envolvimento muito particular, poderíamos até afirmar, em uma metáfora bem brasileira, em uma relação antropofágica com a língua e com a literatura. Por uma espécie de canibalismo amoroso! Canibalismo da letra que é engolida pela palavra, da palavra engolida pelas significações que almejaríamos, imaginariamente, que elas estivessem ao nosso dispor. Como se toda a palavra fosse carregada, ela mesma, por uma ordem possivel do real. Como se letra e palavra fossem urgidas em nosso canibalismo amoroso. E as perguntas que sempre teimavam em aparecer poderiam, nesse início de vida acadêmica, ser resumidas desta forma: o que é escrever; o que é produzir uma escrita autoral; o que é produzir conhecimento pelo ato próprio do escrever; o que fica ou resta daqueles rascunhos todos que estiveram a nossa mercê para que pudéssemos publicar no sentido da oficialidade e da maquinaria do impresso. O que de virtualidade nos esperava e nos alcançava...

Não à toa, nós três fomos aos poucos nos identificando e nos alicerçando naquilo que o jargão da História das Ideias Linguísticas traz como historicidade. A história não apenas de fatos e dados, mas as condições de produção de uma certa memória disciplinar; de um certo controle, pelo institucional, quando da divisão disciplinar, quando de sua história. E nosso maior ensejo sempre foi, nos estudos sobre a língua, "conhecer" também os rascunhos, ou, na expressão de Fenoglio (2013), o nosso "ruminar" na produção do saber sobre e na língua, 
da mesma forma que os sujeitos envolvidos pelo literário interessavam-se pelos manuscritos do sujeito-autor-escritor.

Aos poucos, fomos traçando, cada uma à sua maneira, nossos caminhos, e eles foram encontrando-se, entrecruzando-se ao longo da vida acadêmica (graduação, mestrado, doutorado e pós-doutorado) em uma filiação (e identificação) possivel entre estudante, professora, orientanda, orientadora, supervisora. Aí, a pergunta de nosso interesse foi sendo reelaborada a partir daquelas iniciais que colocamos antes. Começávamos, então, a nos questionar sobre a história e a memória disciplinar na formalização daquilo que ela nos conta, o referendado e já estabelecido. Na verdade, o que gostariamos era poder entender por que contamos a história da Linguística quase sempre de um certo e mesmo ponto. E mais, por que determinar, de antemão, o ponto inicial de nosso disciplinar pelo Curso de Linguística Geral.

Em caminhos pavimentados (e a sempre pavimentar) por todo o percurso acadêmico, conhecemos, através de leituras, a pesquisadora Irène Fenoglio, da École Normale Supérieure, de Paris, no Institut des Textes et Manuscrits Modernes (Item) do Centre National de la Recherche Scientifique (CNRS). Todavia, foi em um encontro casual na Universidade de Buenos Aires, em 2012, em um evento cuja temática era de nosso interesse, que pudemos conversar mais longamente sobre o que fazíamos. De tal encontro nasceu uma relação acadêmica muito forte e os projetos acabaram entrando em cena, na arena do produzir e publicar, além, é claro, na formação de jovens pesquisadores ${ }^{1}$.

Duas das autoras, aqui, em questão, puderam fazer um estágio de doutorado sanduíche de seis e de 12 meses, sob a orientação e a tutela da referida professora. Com ela, aprenderam e consolidaram o quanto a história do conhecimento é cheia de emboscadas e de caminhos tortuosos, o quanto produzir conhecimento não tem como ser retilíneo e horizontal. Produzir conhecimento requer um amadurecimento de questões que antes poderiam parecer fáceis e ser respondidas no imediatismo da surpresa e do entusiasmo inicial. Produzir conhecimento envolve muito mais do que uma simples resposta, envolve um trabalho árduo e consequente, envolvente, é claro; contudo, incessante nas formulações que vão nos afetando em nosso dia a dia de pesquisa e de leituras.

Enquanto uma das autoras trabalhava sobre a história e a memória disciplinar no contexto do Sul brasileiro, as outras duas, em estágio, em épocas diferentes, na École Normale Supérieure de Paris, no Item-CNRS, visitavam acervos, assistiam a cursos e conferências, estudavam, enfim, sobre um mesmo e eterno tema. Enquanto cada uma das duas em Paris, à sua maneira, trabalhava incessantemente, a terceira começava a produzir seus primeiros apontamentos sobre a história da Linguística no contexto dos anos de 1950 a 1980 no Brasil. Das duas em Paris, uma tentava historicizar o lugar do gramático (COSTA, 2015) a partir do seu ato de definir para entender por qual razão, por exemplo, Celso Pedro Luft (o gramático em questão) trazia sem cessar a razão de suas escolhas ancoradas em Ferdinand de Saussure e na obra farol, o Curso de Linguistica Geral; ou seja, o objetivo do estudo de Costa (2015, p. 16) era "propor uma reflexão sobre a contradição que se estabelece entre as diferentes tomadas de posição do sujeito gramático ao produzir conhecimento sobre a língua”. Já a outra 
(SCHNEIDERS, 2014, p. 9) queria entender o que seria determinante para que um estudioso da linguagem no Brasil, como Serafim da Silva Neto, pudesse ter começado a traçar um caminho possivel para a Linguística, dita brasileira, analisando

[...] como o domínio de memória da Linguística é retomado e articulado na constituição discursiva, enfatizando os ecos e as ressonâncias de significação dos já ditos inscritos em determinada produção do conhecimento. Buscando compreender como o processo discursivo é afetado historicamente, a partir da maneira como os saberes da Linguística, via citação do Cours de linguistique générale, estão atravessados e linearizados no fio do discurso.

Portanto, as relações acadêmicas e científicas estabelecidas com a Profa. Irène Fenoglio foram fundamentais também para que, desde 2014, começássemos a nos interessar mais de perto sobre e pelo Curso de Linguística Geral (doravante CLG) e, sobretudo, pelo papel dos manuscritos na história do disciplinar sobre a Linguística de modo mais geral. Nossa questão reelabora-se novamente no como enredamos tal obra nos domínios de uma certa memória do disciplinar quando da dita fundação da Ciência Linguística no mundo ocidental e no como é cada vez mais dificil desenredá-la. Podemos desmanchar os nós que a cercam, que a regem, mas é impossivel não estudar a sua existência duradoura em um efeito metafórico de um nó borromeano à la Lacan (2005). Ou seja, uma aliança, um elo entre o sujeito e seu objeto de desejo, porque o CLG é, pois, entendido como um objeto histórico investido de valores culturais e politicos dos mais variados instituídos disciplinarmente; e, por causa de sua enorme influência para o desenvolvimento da Linguística Moderna no decorrer do século XX, adquire um status de héritage, funcionando como um "dominio de memória" por estabelecer relações de filiações, de gênese, de transformações, de continuidade e de descontinuidade histórica (PUECH, 2013). Impossível, então, de não ser um objeto de desejo de todo sujeito que se interessa pela história da produção do conhecimento linguístico no mundo ocidental, pelo menos.

Diante disso, no presente artigo, refletimos sobre a permanência e inconstância do CLG, bem como a sua capacidade de ser reinventado e manter-se na ordem do dia por mais de um século. Refletimos também sobre o árduo trabalho dos pesquisadores que têm se dedicado ao estudo desse complexo conjunto heterogêneo de textos que se atribui a Saussure para compreendermos o alcance e os limites das teorias que compõem o arcabouço histórico responsável pela fundação da Linguística Moderna e que constitui a Linguística na contemporaneidade. À moda de uma biblioteca (de Babel à la Borges), organizamos nosso texto por estantes (de galerias hexagonais, certamente) para tentar compreender a vastidão e a complexidade do conjunto de obras e documentos que se atribui a Saussure. Convidamos o leitor para passear por essas galerias hexagonais cujas superficies polidas representam e prometem o infinito.

\section{Adentrando Na Biblioteca}

"Basta-me, por ora, repetir o preceito clássico: 'A Biblioteca é uma esfera cujo centro cabal é qualquer hexágono, cuja circunferência é inacessível”' (BORGES, 1941, p. 35).

Inicialmente, chamamos a atenção sobre a problemática em torno das noções de corpus e arquivo naquilo que toca o conjunto heterogêneo de publicações que 
foram editadas por Saussure e atribuídas a ele. As publicações já realizadas em nome de Ferdinand de Saussure e as que estão por vir, incluindo aí também as traduções de tais obras, têm nos permitido imaginar que seria possível dar início a uma biblioteca saussuriana à la Borges.

Essa biblioteca abarcaria o que já foi publicado por Saussure, o que foi publicado em seu nome e também aquilo que virá a ser. Considerando as inúmeras edições dos manuscritos saussurianos e também as diferentes versões do CLG em outras línguas (SCHERER; COSTA, 2018), questionamo-nos se um dia seria possivel chegar a um fechamento acerca da problemática que teve início com a publicação do CLG. Inspiradas na biblioteca de Babel de Borges, preferimos sonhar que as publicações das edições dos manuscritos saussurianos representariam e prometeriam um possivel infinito... À medida que são publicadas novas edições dos manuscritos saussurianos, abrem-se ainda mais questionamentos sobre as publicações anteriores e também sobre as versões em linguas diferentes do CLG.

É importante ressaltar que o CLG recebe significativas alterações conforme vai sendo traduzido em outras linguas e, sobretudo, quando retorna para o francês. A nossa reflexão sobre essa biblioteca de Babel saussuriana tem como ponto de partida o texto de Trabant (2019), que nos faz olhar para o CLG como algo estranhamente familiar. Familiar, uma vez que já o conhecemos, estranhamente porque há nele algo que sempre nos escapa e ele parece tornar-se outro... como uma miragem... ou um livro de areia.

Podemos trazer como exemplo a edição crítica italiana do CLG. Como sabemos, a tradução francês-italiano do CLG foi publicada, em 1967, por Tullio De Mauro, com o acréscimo de uma introdução à edição italiana, notas ao longo do texto e também notas sobre a biografia de Saussure. Posteriormente, em 1972, a edição crítica de Tullio De Mauro foi traduzida do italiano para o francês por Jean-Claude Calvet. Nesse processo de tradução (francês-italiano-francês), o texto saussuriano tornou-se outro, como nos chama a atenção Trabant (2019), e o CLG volta para a língua de Saussure transformado em um novo texto. E, no jogo da lingua que nos coloca Trabant (2019), perguntamo-nos: haveria também uma lingua de Saussure?

Na história filológica do CLG, essa edição crítica possui grande importância, pois não se trata mais do texto inicialmente publicado pelos editores Charles Bally e Albert Sechehaye, mas de um novo e eterno texto que é ressignificado em sua textualidade e na conjuntura histórica em que é acolhido e (re)lido. Desse modo, a edição crítica do CLG seria um texto que se distanciaria do primeiro, como sustenta Trabant (2019). O autor ainda considera que a tradução italiana do CLG (1967), realizada por Tullio De Mauro, reduz a distância entre o CLG e as fontes saussurianas e restitui-lhe a autoria, isto é, "De Mauro, que admira o Curso, não tem nenhum interesse em mostrar a distância entre o Curso e a Fonte, pelo contrário, sua intenção é aproximar os dois, dar um pai ao filho órfão" (TRABANT, 2019, p. 389).

Segundo o autor, Tullio De Mauro deu uma profundidade filológica a essa operação e mudou de forma significativa o texto, de modo que

[...] o Corso é um livro que tem um autor (ou que tenta encontrar um autor: o Corso in cerca d'autore, em busca de autor) e que, por causa disso, diz frequentemente outra coisa do que aquilo que encontramos no que seria o original francês. O Corso é um livro novo, um Curso transformado (TRABANT, 2019, p. 383). 
Cabe ressaltar que a tradução italiana do CLG data da década de 1960, o que significa que o CLG e suas respectivas traduções/versões estão sempre abertos a diferentes interpretações e (res)significações, uma vez que o processo de edição do CLG constitui-se sobre a fragilidade do dispositivo² de escrita do CLG, que, para Trabant (2019), distancia o texto final de sua fonte.

Ainda sobre as edições em língua francesa do CLG, destacamos a edição especial em formato de livro de bolso publicada em 2016, em homenagem aos cem anos de publicação do CLG. Essa edição toma como referência o texto de 1916 e é acrescida de um prefácio de Jean-Didier Urbain. Trata-se de uma outra forma de circulação do mesmo (?) e eterno texto.

\section{O MAPA DA BIBLIOTECA E A COMPLEXIDADE DO ACERVO}

"O UNIVERSO (que outros chamam a Biblioteca) compõe-se de um número indefinido, e talvez infinito, de galerias hexagonais, com vastos poços de ventilação no centro, cercados por balaustradas baixissimas. De qualquer hexágono, vêem-se os andares inferiores e superiores: interminavelmente" (BORGES, 1941, p. 35).

O complexo dispositivo de escrita do CLG é abordado por Kyheng (2007) sob o viés da possibilidade de uma autenticidade dos textos que são atribuídos a Saussure. Kyheng (2007) propõe uma distinção entre arquivo e corpus saussuriano, tomando como critério, para organização, o que ela chama de diferentes graus de autenticidade. Tendo em vista o seu critério da autenticidade, a autora sustenta que o arquivo saussuriano é constituído pelas obras/publicações que são atribuídas a Saussure. Segundo a autora,

[...] por "corpus saussuriano" entendemos o conjunto de textos de Ferdinand de Saussure (obras, artigos, notas, rascunhos, aulas, cartas etc.), e nada senão textos cujo autor legítimo seja o próprio Saussure. Em compensação, por arquivo saussuriano nós entendemos a coleção de documentos historicamente ligados à personalidade de Saussure. Esse arquivo é aberto e recebe textos de muitos autores: os textos de Saussure, mas também o texto do Cours de Linguistiques Générale de Bally et Sechehaye, lembranças, cartas endereçadas a Saussure, documentos de trabalhos identificados como pertencentes a outros autores, tais como as folhas 311-327 das notas sobre a entonação lituana (KYHENG, 2007, p. 2, tradução nossa) ${ }^{3}$.

A distinção entre corpus e arquivo saussuriano, para a autora, tem como problemática central um tema muito caro aos linguistas saussurianos que é a questão da autoria, não só do CLG, mas também de outros textos editados postumamente e atribuídos a Saussure. Nessa busca pelo Saussure "autêntico", em relação ao corpus saussuriano, a autora propõe ainda uma hierarquização segundo o critério da autenticidade, separando aqueles textos cuja versão final foi

2 "Saussure fala (Fonte), escuta + escrita1 dos estudantes (akroatai, fonógrafos), leitura de Bally e Sechehaye dessas notas, escrita2 de Bally e Sechehaye, publicação (impressão): Curso" (TRABANT, 2019, p. 384).

3 "par 'corpus saussurien' nous entendons I'ensemble des textes de Ferdinand de Saussure (ouvrages, articles, notes, brouillons, leçons, lettres, etc.), et rien que les textes dont l'auteur légitime est Saussure lui-même. En revanche, par archive saussurienne nous entendons la collection de documents historiquement liés à la personnalité de Saussure. Cette archive est ouverte et reçoit des textes de plusieurs auteurs: les textes de Saussure, mais aussi le texte du Cours de Linguistiques générale de Bally et Sechehaye, des souvenirs, des lettres adressées à Saussure, des documents de travail identifiés comme appartenant à d'autres auteurs tels que les feuillets 311-327 des notes sur l'intonation lithuanienne." 
estabelecida pelo próprio Saussure e os textos de Saussure que tiveram sua versão estabelecida por terceiros, como é o caso, por exemplo, da publicação da obra Écrits de Linguistique Générale (ELG).

Essa problemática sobre a autoria e sobre o processo de edição do conjunto de textos saussurianos exige dos pesquisadores um trabalho por demais minucioso e remete a um cuidado filológico necessário àquele que se dedica à complexidade do corpus saussuriano. Entretanto, além de tratar-se de uma questão filológica, trata-se de uma questão interpretativa no que toca a essa tentativa de resolver de uma vez por todas a questão centenária: quem é o autor do CLG? Aliás, o historiador da Ciência Linguística, Sofia $(2014)^{4}$, retoma essa questão que, até então, continua em aberto e recusa respostas simplórias. O autor faz uma historicização das discussões em torno dessa temática e aponta os principais argumentos apontados pelos pesquisadores para sustentar a autenticidade (ou não) dos textos saussurianos.

A respeito da discussão sobre a falta de autenticidade do CLG alegada por alguns pesquisadores, Sofia (2014, p. 42, tradução nossa) questiona:

Mas não autêntico do ponto de vista do quê? De um pensamento, uma teoria, de um texto que poderiam ser suscetiveis de ser considerados "autênticos"? Por um momento, digamos, em todo caso, para avançar com prudência, o que seria em grau superior àquele inerente ao CLG. A prudência é aqui estritamente necessária, porque as consequências diferem segundo aqueles que consideram que a autenticidade desse objeto reside na teoria, no texto ou no pensamento que se apresenta ali. Diferentes autores defenderam esses argumentos de maneiras diferentes, alegando provas e recorrendo a critérios cada vez distintos [... $]^{5}$.

Sofia (2014), portanto, pede prudência na busca de uma resposta a essa problemática, uma vez que se trata de uma questão delicada que pode ser abordada sob diferentes pontos de vista e muitos autores renomados apresentaram argumentos consistentes para dar uma resposta única a essa questão. Diferentemente dos autores citados no horizonte de retrospecção, Sofia (2014) não procura uma resposta definitiva para a questão colocada no título do texto, ele não olha para a resposta e, por conseguinte, ele não está lado a lado, na mesma busca, desses pesquisadores.

E continuando com Sofia (2014), ele olha para os argumentos e critérios de cada um dos autores citados com vista a uma possível resposta. Seu interesse não é por uma tomada de posição, mas por entender a complexidade da questão que está posta há mais de um século e por ainda continuarmos a nos perguntar “quem é o autor do CLG?". A pergunta não é simples e, consequentemente, a sua resposta não pode ser simples. Tentar simplificá-la é apagar toda a historicidade e complexidade das discussões que se formaram a respeito.

Para contornar essa problemática sobre a autenticidade (e autoria) dos textos saussurianos, no contexto brasileiro, temos, por exemplo, trabalhos importantes e fundamentais, como é o caso de Fiorin, Flores e Barbisan (2013), que propõem as noções de corpus saussuriano e corpus de pesquisa. Segundo os autores,

4 Estanislao Sofia é, atualmente, bolsista Jovem Talento do Programa Institucional de Internacionalização (Capes-PrInt - UFSM) no Laboratório Corpus e Centro de Documentação e Memória.

5 "Mais inauthentique vis-à-vis de quoi? D'une pensée, d'une théorie, d'un texte qui seraient susceptibles d'être considérés, eux, comme 'authentiques'? D'une instance, disons en tout cas, pour avancer avec prudence, qui le serait à un degré supérieur à celui inhérent au CLG. La prudence s'avére ici strictement nécessaire, car les conséquences diffèrent selon qu'on considère que l'inauthenticité de cet objet réside dans la théorie, dans le texte, ou dans la pensée qu'on y présente. Différents auteurs ont défendu ces arguments de diferentes manières, en alléguant des preuves et en recourant à des critères chaque fois distincts [...]." 
[...] tal divisão não obedece a critérios de autenticidade das fontes. O corpus saussuriano é o conjunto de documentos constituido por fontes de natureza heterogênea cuja existência não parece ser negada por nenhuma das partes que integram a arena da polêmica. Kyheng chama-o de arquivo. A denominação para nós é o ponto de menos importância. Interessa-nos apenas resguardar a existência de um conjunto heterogêneo de fontes. $O$ corpus de pesquisa é o recorte que se faz do conjunto, tendo em vista os objetivos da pesquisa (FIORIN; FLORES; BARBISAN, 2013, p. 16).

Os autores são categóricos recusando o critério de autenticidade, o que seria para eles como que iniciar uma busca por um verdadeiro Saussure em contraponto a um falso Saussure. O que os autores propõem

não diz respeito a um suposto valor de verdade que as fontes teriam se contrapostas entre si. Não se trata de defender que uma fonte é mais 'verdadeira' que outra, trata-se apenas de resguardar as especificidades que cada fonte tem (FIORIN; FLORES; BARBISAN, 2013, p. 17).

Desde que o CLG foi publicado, a autoria da obra é problematizada e o critério de autenticidade dos textos saussurianos é um tema bastante delicado e debatido, separando aqueles que entendem que o CLG não poderia ser atribuído a Saussure e aqueles que defendem que o CLG é tão autêntico quanto o ELG, que também é atribuído a Saussure, todavia não foi publicado por ele. Desse modo, muitos pesquisadores não fazem distinção entre corpus e arquivo saussuriano, logo não fazem distinção entre os textos mais ou menos "autenticamente" saussurianos e consideram apenas a noção de corpus saussuriano, que compreende os textos publicados por Saussure e também aqueles em seu nome.

De antemão, é preciso destacar que, de nossa parte, não defendemos a hierarquização de autenticidade dos textos saussurianos. Entendemos que se trata de textos de natureza distintas que precisam ser considerados por aquilo que são e, principalmente, é urgente que se reflita sobre os critérios de edição de manuscritos tão complexos. Além disso, acreditamos que as questões que abordamos aqui são basilares para qualquer pesquisador que se debruça sobre os textos saussurianos e nenhum pesquisador pode alegar desconhecê-las ou ignorá-las.

À parte da noção de corpus e arquivo saussuriano, para não ter que abordar o conjunto de textos saussurianos por uma temática de autenticidade, propomos uma outra organização, considerando também os desdobramentos dos textos saussurianos e a sua capacidade de tornar-se outro e ser sempre o mesmo. Vejamos!

\section{Galeria hexagonal 1: DOS Textos escritos e publicados POR Ferdinand de Saussure}

"Os homens costumam inferir desse espelho que a Biblioteca não é infinita (se o fosse realmente, para quê essa duplicação ilusória?), prefiro sonhar que as superficies polidas representam e prometem o infinito..." (BORGES, 1941, p. 35).

Essa é a primeira galeria que dá início ao nosso adentramento no acervo de Saussure; contudo, é preciso reconhecer que, resguardada a sua devida importância, não foi esse conjunto de textos que consagrou o mestre genebrino. Como 
sabemos, Saussure ficou conhecido, sobretudo, por aquilo que ele não publicou, mas foi publicado em seu nome. Em vida, Saussure publicou muito pouco. Suas publicações resumem-se a um número limitado de textos que só vieram à luz por uma exigência acadêmica.

Uma das primeiras publicações de Saussure foi aos 21 anos, em 1879, em Leipzig, quando ele publicou o seu célebre Mémoire sur les système primitif des voyelles dans les langues indo-européenes ${ }^{6}$. Dois anos depois, em 1881, Saussure publicou sua tese de doutorado intitulada De l'emploi du génitif absolu en sanscrit? A maior parte das publicações de Saussure foi reunida por Charles Bally e Léopold Gautier e publicada, em 1922, sob o título Recueil des publications scientifiques de Ferdinand de Saussure ${ }^{8}$.

A esse conjunto de textos, poderiamos (mas não deveriamos) acrescentar ainda as cartas trocadas entre Saussure e outros linguistas, como "Lettres de

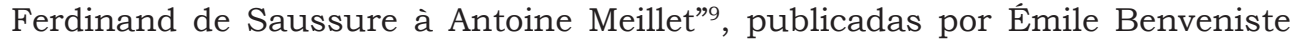
na revista Cahiers Ferdinand de Saussure (doravante Cahiers), n. 21, de 1964 (p. 89-135). Entretanto, é preciso aí um pouco de cautela, pois se trata de cartas que foram escritas por Saussure, porém publicadas por terceiros. É preciso considerar ainda que se trata de textos que, ainda que a temática seja de interesse de outros linguistas, não foram escritos para ser divulgados publicamente. Sua versão final foi estabelecida por outrem, isto é, a forma como é tornada pública é mediada por outros que não o autor do texto. Essa problemática leva-nos, então, para a segunda galeria da biblioteca.

\section{Galeria hexagonal 2: dos textos escritos POR Ferdinand de SAUSSURE E PUBLICADOS POR TERCEIROS}

"A Biblioteca existe ab aeterno. Dessa verdade cujo corolário imediato é a eternidade futura do mundo, nenhuma mente razoável pode duvidar. O homem, o imperfeito bibliotecário, pode ser obra do acaso ou dos demiurgos malévolos; o

Universo, com seu elegante provimento de prateleiras, de tomos enigmáticos, de infatigáveis escadas para o viajante e de latrinas para o bibliotecário sentado, somente pode ser obra de um deus" (BORGES, 1941, p. 36).

Talvez, o lugar mais adequado para guardar as referidas cartas publicadas na revista Cahiers $^{10}$ seja nessa segunda galeria. Aliás, boa parte da coleção dessa revista merece ser guardada nessa galeria, pois se trata de um periódico fundado em 1941, na Universidade de Genebra, sob a direção da Societé Genevoise de Linguistique (Sociedade Genebrina de Linguística). Essa associação também foi criada em 1941 e, segundo seu estatuto, tem como objetivo:

[...] contribuir de uma forma geral para o avanço da ciência linguística, principalmente, estudando os sistemas de línguas à luz dos princípios e dos métodos de Ferdinand de Saussure: para reuniões e discussões periódicas; publicando, se as circunstâncias permitirem, ao menos uma vez por ano, uma publicação

\footnotetext{
Disponível em: https://gallica.bnf.fr/ark:/12148/bpt6k729200/f1.image.textelmage. Acesso em: 22 jul. 2020.

Disponível em: https://archive.org/details/delemploidugni00sausuoft/page/6/mode/2up. Acesso em: 22 jul. 2020.

Disponível em: https://gallica.bnf.fr/ark:/12148/bpt6k214790/f3.image. Acesso em: 22 jul. 2020.

Disponível em: https://www.cercleferdinanddesaussure.org/CFS/Volume_21_1964.pdf. Acesso em: 22 jul. 2020.

10 Disponível em: https://www.cercleferdinanddesaussure.org/les-cahiers-ferdinand-de-saussure/cahiers-ferdinand-de-saussure-1-601941-2007/ Acesso em: 22 jul. 2020.
} 
periódica, os CAHIERS FERDINAND DE SAUSSURE (Cadernos Ferdinand de Saussure), publicados pela Sociedade Genebrina de Linguística contendo um ou mais trabalhos originais, resenhas de publicações recebidas e a ata das sessões (CAHIERS, 1941, p. 26, tradução nossa) ${ }^{11}$.

O primeiro comitê que esteve na fundação da Sociedade Genebrina de Linguística foi composto por Charles Bally, Albert Sechehaye, Serge Karcevski, Léopold Gautier, Henri Frei e Samuel Baud-Bovy. E o primeiro número da revista Cahiers foi destinado a comemorar duas datas: 1. o cinquentenário do aniversário da Cadeira de História e de Comparação das Línguas Indo-europeias e de Sânscrito, criada na Université de Genève por Ferdinand de Saussure em 1891; 2. o 25º aniversário do CLG, publicado pela primeira vez em Lausanne, em 1916.

Nessa revista também foram publicadas, pela primeira vez, por Robert Godel, em 1954, as notas manuscritas de Saussure encontradas posteriormente à publicação do CLG, mas são anteriores aos cursos, isto é, datam de antes de 1900 . Essa publicação deu início aos trabalhos de exegese dos quais se ocupam hoje inúmeros pesquisadores. Cabe ressaltar que essas notas foram escritas por Saussure, porém tornadas públicas por Godel, o qual pontua o fato de serem notas inconclusas que não visavam a uma publicação.

Desse modo, destacamos a diferença entre o manuscrito propriamente dito e a edição desses manuscritos. Essas notas, em específico, tornam-se públicas a partir da edição proposta por Robert Godel, que não é o manuscrito, apenas o representa. Reforçamos esse caráter de representação do manuscrito, uma vez que a edição das notas pressupõe também a passagem de um texto escrito à mão, com inúmeras marcas de reticências e visivelmente inacabado e inconcluso, para um texto editado em uma maquinaria outra, de outro tipo, a edição. Nessa passagem do texto manuscrito ao texto editado, muita especificidade perde-se, como as rasuras, as escritas à margem, os esquemas... enfim... marcas que são próprias de um texto manuscrito em elaboração e que se perdem quando esse texto é editado, para impressão. É nesse sentido que entendemos o texto editado como uma representação do manuscrito e, portanto, eles não são equivalentes e um não substitui o outro.

Ao lado das notas manuscritas editadas e publicadas na revista Cahiers, colocaremos as notas editadas e publicadas na obra ELG (2002), editadas por Rudolf Engler e Simon Bouquet. Essa obra atribuída a Saussure traz novamente as notas que já haviam sido publicadas por Robert Godel na revista Cahiers, em 1954, e também algumas notas inéditas que foram encontradas na década de 1990. Ainda, guardaremos também aqui a obra Science du langage - de la double essence du langage (2011), editada por René Amacker. Essa obra é uma edição crítica de notas saussurianas encontradas em 1996, publicação dedicada por Amacker à memória de Rudolf Engler, um dos editores da publicação francesa. Em outro momento (SCHERER; COSTA, 2019), pontuamos algumas diferenças entre tais edições e como, ao ser retomado, em momentos diferentes e por sujeitos diferentes, o texto ganha uma nova/outra-eterna forma. Nesse sentido é que insistimos que não devemos tomar como equivalentes o manuscri-

11 "contribuer d'une façon générale à l'avancement de la science linguistique, principalement en étudiant les systèmes de langues à la lumière des principes et des méthodes de Ferdinand de Saussure: par des réunions et des discussions périodiques; en publiant, si les circonstances le permettent, au moins une fois par année, un organe, les CAHIERS FERDINAND DE SAUSSURE publiés par la Société Genevoise de Linguistique contenant un ou plusieurs travaux originaux, le compte rendu de publications reçues et le procès-verbal des séances." Disponível em: https://www.cercleferdinanddesaussure.org/CFS/Volume_1_1941.pdf. Acesso em: 22 jul. 2020. 
to e a edição do manuscrito, pois ambos não são iguais e tampouco partilham da mesma natureza.

Guardaremos também nessa galeria, com a coleção da revista Cahiers, a obra Une vie en lettres (2014), cuja autoria é atribuída a Saussure. Trata-se de uma publicação, editada por Claudia Mejía Quijano, de cartas escritas por Ferdinand de Saussure endereçadas a linguistas, e, especialmente, a sua família e amigos. Desse modo, a temática abordada nas cartas é variada e não necessariamente diz respeito à Linguística. São cartas de cunho pessoal trocadas com pessoas próximas, entre as quais destacamos, por exemplo, as cartas enviadas a sua esposa Marie, a seus filhos e a seus irmãos, todas escritas com muita subjetividade, própria de uma textualidade de cunho familiar.

Ainda que possa causar estranhamento, caro leitor, guardaremos nessa galeria um exemplar de Anagrammes homériques (Anagramas homéricos), editados por Pierre-Yves Testenoire, publicado em 2013. O referido estranhamento poderia ser justificado por uma interpretação sustentada por alguns autores que insistem em dissociar o Saussure do CLG e o Saussure dos anagramas. De nossa parte, não fazemos essa distinção, ainda que, neste texto, tenhamos dado uma ênfase maior aos textos referentes à Linguística Geral, especialmente aqueles em torno do CLG. Não nos alongaremos mais sobre essa temática, uma vez que esse não é o propósito do presente texto. Como apontamos anteriormente, não estabeleceremos aqui uma hierarquização sob quaisquer critérios dos textos saussurianos e nenhuma separação que possa desvincular uma pesquisa da outra ou o autor de seu texto. Nosso ensejo é bem mais modesto: imaginar uma biblioteca saussuriana que está sendo constantemente alimentada e organizar as sucessivas publicações que têm vindo à luz a partir do legado saussuriano. Essa galeria tem uma peculiaridade: ela é rondada por um espectro que está em constante manutenção com as póstumas publicações em nome de Saussure.

Portanto, nessa galeria guardaremos os textos escritos por Saussure e encontrados sob a forma de manuscrito e que foram tornados públicos posteriormente por terceiros. Não guardaremos aqui o manuscrito propriamente dito, apenas a sua edição estabelecida por outro sujeito que não Saussure.

\section{Galeria hexagonal 3: dos textos publicados atribuídos a Ferdinand DE SAUSSURE}

"A luz procede de algumas frutas esféricas que levam o nome de lâmpadas. Há duas em cada hexágono: transversais. A luz que emitem é insuficiente, incessante. Como todos os homens da Biblioteca, viajei na minha juventude; peregrinei em busca de um livro, talvez do catálogo de catálogos” (BORGES, 1941, p. 35).

Nessa galeria, não exatamente numa estante, mas sob uma cúpula transparente, com uma iluminação incidindo de cima para baixo direta e pontual, colocaremos o volume que deu início a uma série de discussões que se estendem até hoje: o Cours de Linguistique Générale (1916). Como sabemos, Saussure não escreveu a obra que hoje conhecemos como CLG e, como os próprios editores admitem no prefácio à primeira edição, provavelmente, Saussure não teria autorizado a sua publicação. Nesse caso, precisamos recuperar aqui o dispositivo de escrita do CLG para justificarmos o porquê de estarmos guardando-o aqui nessa galeria.

Saussure ministrou uma série de três cursos de Linguística Geral entre os anos de 1907 e 1911, na Universidade de Genebra. A partir dos cursos ministra- 
dos oralmente por Saussure, os alunos tomaram notas em seus cadernos. Além disso, é preciso ponderar também que, tendo em vista a extensão dos cursos e o distanciamento das datas, o público não era exatamente o mesmo nos três cursos. Após a morte do mestre, Charles Bally e Albert Sechehaye, professores da Universidade de Genebra e colegas de Saussure, tomaram a iniciativa de publicar, sob a forma de livro, as notas de Saussure referentes aos cursos ministrados.

No entanto, segundo os editores, o que eles encontraram, naquele momento, seria insuficiente para um livro e decidem, então, por uma reconstrução apoiada, sobretudo, no terceiro curso. Os editores tomaram, como base da reconstrução, as notas de Saussure e também as anotações dos alunos. Como Charles Bally e Albert Sechehaye não assistiram aos cursos, eles contaram com a colaboração de Albert Riedlinger, que assistiu aos dois primeiros cursos.

Ao longo desse processo de reconstrução, os editores depararam-se com algumas dificuldades, especialmente quando os cadernos, ao serem comparados, apresentaram posições peculiares na tomada de notas, algumas vezes completamente discordantes. Apesar de todos os percalços, os editores concluem que esse projeto seria audacioso e publicam, em 1916, a obra que eles chamam de Cours de Linguistique Générale e atribuem a autoria a Saussure, ainda que não tenha participado (diretamente) do processo de escrita do texto. Em síntese, o dispositivo de escrita do CLG poderia ser resumido na seguinte equação (TRABANT, 2019, p. 384, cf. nota 2):

Saussure fala (Fonte), os alunos escutam + escrita 1 dos estudantes (anotações) + Leitura de Bally e Sechehaye dessas notas + escrita 2 de Bally e Sechehaye + publicação (impressão) = CLG.

Esse dispositivo de escrita dá um ar peculiar ao CLG e, curiosamente, é justo essa obra que alçou a Linguística ao âmbito das Ciências Humanas, colocando Saussure como o fundador da Ciência Linguística. Por isso, esse exemplar está no centro de uma galeria, não em uma estante, no centro da biblioteca.

Nessa galeria, damos ênfase ao CLG, que, como destacado no início de nossa reflexão, é uma obra bastante controversa, sobretudo por ela não ter sido publicada por aquele a quem se atribui a autoria. Junto ao CLG, guardaremos um exemplar da publicação intitulada La "collation Sechehaye" du "Cours de Linguistique Générale" de Ferdinand de Saussure (2015), editada por Estanislao Sofia. Trata-se de uma edição diplomática das notas manuscritas de Albert Sechehaye daquilo que posteriormente viemos a conhecer como Cours de Linguistique Générale. Nessa edição, o leitor encontrará, de um lado, a imagem em alta qualidade do manuscrito (fac-símile) e, de outro, a edição do manuscrito, a qual preserva e reproduz todas as minúcias e filigranas. O primor e o cuidado da edição permitem-nos concluir que se refere a uma edição elaborada por um saussuriano apaixonado por seu trabalho para saussurianos que amam o que fazem. Essa edição diplomática proposta por Estanislao Sofia ${ }^{12}$ nos traz à memória um outro conto de Borges, "Sobre o rigor da Ciência". Nesse conto, os cartógrafos se debruçam sobre a criação de um mapa extremamente preciso e minucioso e

12 Nota ao leitor: por favor, não se zangue por mais uma digressão no nosso texto, mas não podemos deixar de mencionar o $123^{\circ}$ Seminário de Estudos Avançados - O estudo da obra de Ferdinand de Saussure: problemas teóricos, filológicos e editoriais, realizado nos dias 3 e 4 de junho de 2019, no Centro de Documentação e Memória, em Silveira Martins (campus UFSM). O seminário foi ministrado por Estanislao Sofia e abordaram-se os conceitos de sistema e de valor nos manuscritos saussurianos, além, é claro, do complexo processo de edição do CLG, o qual implica também pensar a problemática da autoria da referida obra. 
criam, então, o mapa em escala 1:1, no qual um centímetro sobre o mapa representava um centímetro sobre o terreno.

Em relação ao corpus saussuriano, demos maior destaque ao CLG por várias razões, mas, especialmente, porque, apesar do seu polêmico processo de edição, é a obra que promoveu um bouleversement na história na Linguística. Na década de 1960, quando essa obra contribuiu para que a Linguística fosse aclamada a ciência-piloto das Ciências Humanas no seio do Estruturalismo, as fontes consultadas para a elaboração do CLG já haviam sido publicadas em edições criticas e havia uma forte discussão sobre tal problemática, como a obra de Robert Godel, Les sources manuscrites du Cours de Linguistique Générale (1957). Aqueles que apostavam na cientificidade do CLG e na sua importância para alçar a Linguística ao âmbito de Ciência pareciam indiferentes às edições críticas e às discussões que estavam ocorrendo; todavia, elas não afetaram o lugar que a referida obra já havia adquirido no estruturalismo vigente.

A par do complexo processo de edição do CLG, e também dos diferentes momentos históricos em que ela foi recebida na história da Linguística no Ocidente, essa obra está no cerne daquilo que ficou conhecido entre os estruturalistas como corte epistemológico saussuriano. Aliás, "epistemologia" é uma palavra que não existia no sentido dado a sua atualidade na época de Saussure, como destaca Simon Bouquet (2012, p. 22, tradução nossa):

Saussure não fala de epistemologia, no sentido que nós a entendemos - a palavra não existia na sua época -, mas seu pensamento não é menos autenticamente epistemológico, particularmente no que ele permite colocar critérios gerais de legalidade científica para a linguística ${ }^{13}$.

Para os estruturalistas, esse (dito) corte foi constituído em torno da definição de um objeto para a Linguística, que é a língua. Por sua vez, a noção de "corte epistemológico" vem de uma perspectiva ocidental de Ciência que predominou durante a década de 1960 e estendeu-se até os anos 1980, apoiando-se na noção proposta pelo filósofo francês Gaston Bachelard como ponto de ruptura, de não retorno. O autor defende a não continuidade das Ciências, sustentando que,

[...] em tal formigamento de descobertas, como não ver que toda linha de continuidade é sempre um traço demasiado rústico, um esquecimento da especificidade de pormenores? De resto, é preciso pedir aos próprios cientistas a consciência das descontinuidades da ciência contemporânea. Eles determinam essas descontinuidades com todo o rigor desejável (BACHELARD, 1983, p. 173).

O filósofo apoia-se em uma perspectiva da descontinuidade das Ciências, a qual contribuiu também para legitimar o lugar de Saussure como o precursor da Linguística Moderna. Além disso, ao lado da noção de corte epistemológico, aparece também a noção de descoberta, tomada no sentido moderno ${ }^{14}$ do termo, entendida aqui como "um resultado, particularmente importante do ponto de vista cognitivo e epistemológico, atingido no decorrer de um processo de busca" (DESCENDRE, 2015, p. 22-23).

13 "Saussure ne parle pas d'épistémologie, au sens où nous l'entendons - le mot n'existait pas à son époque - mais sa pensée n'en est pas moins authentiquement épistémologique, notamment en ce qu'elle permet de poser des critères généraux de légalité scientifique pour la linguistique."

14 Sobre a noção de descoberta, ver Descendre (2015). 
No caso da Linguística, qual teria sido essa descoberta? O que foi que Saussure descobriu? Não dizemos que Saussure descobriu o objeto da Linguística, mas dizemos que ele definiu ${ }^{15}$ tal objeto. Aliás, a noção de descoberta nas Ciências Humanas é um tanto delicada. Sériot (2015) aponta essa problemática ao refletir sobre o objeto de conhecimento nas Ciências Humanas. Para ser descoberto, tal objeto precisaria preexistir ao conhecimento. De fato, as linguas, enquanto objeto real, existem e preexistem a qualquer conhecimento linguístico. Entretanto, é a partir da problemática saussuriana que a noção de língua vai ser tomada enquanto um conceito teórico e como objeto de conhecimento da Linguística.

A nosso ver, o que temos com a edição e publicação do CLG é uma espécie de objeto de predileção para os historiadores das ideias, em nosso caso, na História Social da Linguística, pois ele, o CLG, acaba, nas palavras de Starobinski (2011), formando uma ideia com unidade semântica capaz de articular com outras unidades semânticas, dando a ver o como podemos articular ciência, história e memória na história da produção do conhecimento. De outro lado, por muito tempo, a história da Linguística organizou-se em torno do CLG, tomando-o como um ponto de ruptura. Segundo Courtine (2006, p. 5),

[...] a reflexão sobre a história da disciplina estava, com efeito, dominada pelo que poderiamos comodamente chamar de "saussurologia", isto é, a idéia segundo a qual o advento de uma linguística científica tinha se fundado sobre um “corte epistemológico", que intervém no Cours de Linguistique Générale.

O autor reforça ainda que o CLG inspirou o estruturalismo, o qual supunha encontrar ali um modelo de cientificidade. Contudo, no auge do estruturalismo linguístico europeu, esperavam-se da Linguística respostas que ela não tinha condições de oferecer (PAVEL, 1990). Desse modo, é preciso ter em vista que hoje essa leitura é considerada datada, representativa de uma dada conjuntura histórica e ideológica. Sobre esse aspecto, Normand (2009, p. 18-19) aponta o seguinte:

[...] considerado no desenvolvimento das ciências da linguagem, para a maior parte dos linguistas de hoje, o momento saussuriano é datado e, por isso mesmo, ultrapassado, qualquer que tenha sido sua consequência histórica. [...] Mas ele é ainda um texto de ideias, de reflexão absolutamente original sobre a linguagem, a especificidade do objeto-lingua, as armadilhas da evidência e da trivialidade nas ciências humanas, e, como tal, sua leitura torna-se estimulante, mesmo para os linguistas.

Tomado um certo distanciamento temporal, em consonância com as ideias de Normand (2009), Courtine (2006, p. 6) afirma ainda:

[...] a constituição de uma memória da linguística por meio da historiografia recente desenha-se, assim, numa outra concepção. Ela vem, sem negar a importância do acontecimento científico que representou o Cours, relativizar, no entanto, o alcance do "corte saussureano" na história da disciplina.

15 Destacamos aqui a importância de refletir sobre a noção de "definição" para a constituição da história da produção do conhecimento. Costa (2012, p. 34) defende que "a definição poderia ser considerada uma formulação singular na medida em que expõe o sujeito à visibilidade a partir do gesto interpretativo. Além disso, a forma da definição projeta um efeito de fechamento para que não signifique outra coisa a não ser o que o sujeito espera que signifique, ao mesmo tempo em que mascara o gesto interpretativo, fazendo parecer que o dizer é da ordem da evidência e que o sujeito é exterior ao seu dizer. Dessa forma, entendemos que definir poderia ser considerado um gesto singular que coloca o sujeito como responsável por aquilo que diz e escreve, simulando estar na origem do seu dizer, como se as palavras não tivessem história". 
Nesse sentido, o autor aponta a importância das pesquisas realizadas por Sylvain Auroux (1989) e Jean-Louis Chiss e Christian Puech (1987), que contribuíram para refletir sobre a história da Linguística recente e sobre o CLG enquanto um lugar de memória. Não vamos trazer aqui todo um trajeto de pesquisa e de produção de estudiosos importantes que mostram o quanto, além do CLG, outros textos também foram atribuídos a Saussure. Nosso interesse de estudo, vale lembrar novamente, está centrado no CLG e no quanto ele garante uma possivel escritura da história da Ciência Linguística. Para nós, "Só haveria leitura completa naquela que transformaria o livro em uma rede simultânea de relações recíprocas"16 (ROUSSET, 1964, p. xiii, tradução nossa). Entrar em uma obra é entrar em um universo outro, é mudar de universo. É abrir um outro horizonte. Estudá-la é impor um acontecimento e abrir-se para novos parâmetros e novos dizeres na luta entre forma e significação, para ressignificar.

\title{
Galeria hexagonal 4: DAS TRADUÇões do CLG
}

\author{
“'Não há, na vasta Biblioteca, dois livros idênticos'. Dessas premissas \\ incontrovertíveis deduziu que a Biblioteca é total e que suas prateleiras \\ registram todas as possíveis combinações dos vinte e tantos símbolos \\ ortográficos (número, ainda que vastíssimo, não infinito), ou seja, tudo o \\ que é dado expressar: em todos os idiomas" (BORGES, 1941, p. 37).
}

Guardaremos nessa galeria as diferentes traduções do CLG que dão uma nova coloração ao texto, que varia conforme o lugar de circulação e as condições históricas em que é recebido. Essa passagem de uma língua a outra não é automática, e é essa natureza da(s) língua(s) que assegura também a permanência e a atualização do CLG.

Desse modo, cabe ressaltar que, na época em que foi publicado, o CLG não foi nenhum best-seller e, segundo Normand (2009, p. 16), "suscitou interesses e críticas sem que ninguém visse nele um barril de pólvora suscetivel de ser ameaça à tradição universitária”. A primeira tradução do CLG só foi publicada mais de uma década depois e não foi na Europa. Segundo Salum (2006, p. XIII-XIV),

A primeira foi a versão japonesa de H. Kobayashi, de 1928, reeditada em 1940, 1941 e 1950. Vem depois a alemã de H. Lommel, em 1931, depois a russa, de H. M. Suhotin, em 1933. Uma divulgou-o no Oriente, e a outra no mundo germânico (e nórdico) e a terceira no mundo eslavo. A versão espanhola, de Amado Alonso, enriquecida com um excelente prefácio de 23 páginas, saiu em 1945, sucedendo-se as edições de 1955, 1959, 1961, 1965 e 1967, numa cerrada competição com as edições francesas. São as edições francesa e espanhola os veículos de maior divulgação do Cours no mundo românico.

Já a edição italiana, como vimos anteriormente, foi publicada, em 1967, por Tullio De Mauro, como ressalta Trabant (2019, p. 382): "A tradução italiana demora a chegar, visto que a tradução japonesa data de 1928 e a alemã, de 1931. Os italianos não precisavam da tradução para ler o Curso. Mas eles o leram com certa reserva".

16 "Il n’y a de lecture complète que celle qui transforme le livre en réseau simultané de relations reciproques." 
A tradução brasileira foi publicada somente em 1970, com 54 anos de atraso, como ressalta Isaac Nicolau Salum, no prefácio à edição brasileira do CLG. É preciso destacar ainda que, no Brasil, diferentemente do que acontece na Europa, não há uma tradição sobre estudos voltados à Linguística Geral. Há, sobretudo, uma tradição de estudos normativos, filológicos e dialetológicos (MATTOSO CÂMARA JR., 1976).

Quando o CLG foi publicado no Brasil, na década de 1970, ele já não tinha mais a mesma importância na Europa, especialmente a que havia alcançado nas décadas de 1950 e 1960, no seio do movimento estruturalista. O Brasil, naquele momento, manteve-se alheio à recepção que a referida obra tivera na Europa e toda repercussão em torno do processo de edição ao qual esteve submetida, à publicação das fontes manuscritas consultadas, bem como às edições críticas que então surgiram. O contexto de recepção do CLG no Brasil é outro, e isso tem implicações também sobre a leitura que é feita dessa obra (cf. FLORES, 2017).

Em outro momento (SCHERER; COSTA, 2018), analisamos as versões brasileira, portuguesa e argentina do CLG, especialmente seus textos introdutórios, e comparamos uma passagem específica do CLG. Esse estudo permitiu-nos compreender que, a cada tradução, há uma atualização do texto que é sensivel às condições históricas em que se inscreve e também ao gesto interpretativo identificatório do tradutor e do editor. A tradução da edição crítica do CLG ainda não foi publicada no Brasil, mas temos a publicação da tradução da introdução, escrita por Tullio De Mauro (2018), à edição crítica do CLG. A tradução da introdução tem como base a publicação francesa do CLG de 1974. Por se tratar de uma introdução de uma obra, as tradutoras decidiram não dar outro título ao texto senão “...” (sim, leitor, são reticências), uma vez que também não caberia, fora do CLG, chamá-lo de "introdução", ainda que não deixe de ser a "introdução" do CLG.

Nessa galeria, guardaremos as traduções do CLG, as mencionadas aqui e também aquelas que não foram, mas que são igualmente importantes, pois nos permitem imaginar um mapa de circulação do CLG, bem como a importância das ideias saussurianas para pensar a noção de língua em diferentes lînguas do mundo. Essa galeria das traduções do CLG justificaria ainda mais uma biblioteca saussuriana à moda de "A Biblioteca de Babel", de Borges.

\section{Galeria hexagonal 5: "Para além do ClG" ou "O acervo É ainda MAIS VASTO E PROMETE O INFINITO"}

"Quando se proclamou que a Biblioteca abarcava todos os livros, a primeira impressão foi de extravagante felicidade. Todos os homens sentiram-se senhores de um tesouro intacto e secreto. Não havia problema pessoal ou mundial cuja eloquente solução não existisse: em algum hexágono. O Universo estava justificado, o Universo bruscamente usurpou as dimensões ilimitadas da esperança" (BORGES, 1941, p. 37).

Saussure ficou conhecido, sobretudo, pelo CLG. Entretanto, as notas manuscritas do mestre não se resumem só à Linguística Geral e às cartas pessoais. Entre os manuscritos encontrados, há pesquisas bastante avançadas sobre anagramas e também sobre lendas germânicas distribuídas em numerosos cadernos. Esses estudos interessam não só a linguistas, mas também a antropólogos e literatos. Os cadernos sobre anagramas mais antigos datam de 1906 e 
reportam-se a textos poéticos (latinos, gregos, védicos), especialmente de autores como Homero, Virgílio, Catulo, Horácio e Ovídio. A publicação de Jean Starobinski, Les mots sous les mots (1971), traduzida no Brasil como As palavras sob as palavras (1974), contribuiu de forma significativa para a divulgação desses estudos que parecem ter ocupado uma grande atenção do mestre genebrino, a julgar pela quantidade de cadernos encontrados voltados aos estudos de anagramas, à métrica védica e aos versos saturninos. Segundo o autor, "esses cadernos, classificados por Robert Godel, encontram-se na Biblioteca de Genebra. Estão distribuídos em oito caixas, cada qual designada por um registro diferente" (STAROBINSKI, 1974, p. 7). Entre os cadernos mencionados, Starobinski (1974, p. 8) destaca que "a exposição teórica tomou uma forma mais acabada no Premier cahier à lire préliminairement (Ms. fr. 3963). Ele poderia ter sido preparado visando a uma publicação, à qual Ferdinand de Saussure preferiu renunciar". Esse caderno faz parte de um conjunto de 24 cadernos registrado como "Anagramas: Homero" (Ms. fr. 3963). Esse conjunto, especialmente, foi objeto de estudo da tese de doutorado de Pierre-Yves Testenoire, defendida em 2010 e publicada em forma de livros em 2013, pela editora francesa Éditons Lambert-Lucas (cf. também SAUSSURE, 2013). No caso do contexto brasileiro, também temos pesquisas bastante significativas no que tocam aos anagramas saussurianos, como a dissertação de mestrado e a tese de doutorado de Marcen de Oliveira Souza, respectivamente: Os anagramas de Saussure: entre a poesia e a teoria (2012), posteriormente publicada como livro, em 2018, sob o mesmo título, e Os anagramas de Saussure: um percurso pelo lado pitoresco das línguas (2017).

Não nos estenderemos aqui mencionando todos os trabalhos que têm sido desenvolvidos a partir do corpus saussuriano ao longo desses mais de cem anos, pois isso seria muito pretensioso e contraditório em relação à posição teórica que assumimos. Tendo em vista a abundância de publicações que são dedicadas aos estudos saussurianos, guardaremos, portanto, nessa galeria as publicações de pesquisadores que têm contribuído para a divulgação dos manuscritos saussurianos, ressaltando a importância do trabalho desses pesquisadores para a compreensão do legado saussuriano. Não estamos nos referindo àquelas publicações que são editadas em nome de Saussure (essas estão na galeria hexagonal 2). Estamos nos referindo aos trabalhos de diferentes pesquisadores que se debruçam sobre os textos saussurianos e trazem à luz novas/eternas leituras sobre o corpus saussuriano, contribuindo, desse modo, para a sua constante atualização e permanência. A esses trabalhos já publicados até o momento se somarão aqueles que virão a ser, sendo importante ressaltar que, conforme aponta Sofia (2012, p. 36, tradução nossa),

Com efeito, sobre um total aproximado de 30.000 páginas escritas, divididas entre a Bibliothèque de Genève et la Houghton Library de Harvard, revelando projetos e períodos heteróclitos, menos de um décimo do todo foi estudado, editado e publicado ${ }^{17}$.

Considerando esse horizonte de retrospecção (AUROUX, 2008) que compreende mais de um século em torno do legado saussuriano e a potencialidade de

17 "En effet, sur un total d'environ 30.000 pages écrites, réparties entre la Bibliothèque de Genève et la Houghton Library de Harvard et relevant projets et périodes hétéroclites, moins d'une dixième partie a été étudiée, éditée et publiée." 
futuro que as notas manuscritas inéditas saussurianas prometem, essa galeria, portanto, fica em aberto e promete, quem sabe, assim como "A Biblioteca de Babel", de Borges, o infinito.

Portanto, impossivel pensar em um desfecho, impossivel pensar na probabilidade de um ponto de vista autoral sobre a leitura, sobre a tradução, sobre a versão, sobre os comentários às notas, sobre a edição de manuscrito a ou b, porque sempre haverá uma cena por demais esquecida, sedimentada, pavimentada em cada uma das palavras de cada pesquisador, leitor, estudioso redimensionando o lugar do leitor.

Toda leitura é alteração, alternada e possuída, pois Cerquiglini (1989, p. 19, tradução nossa), comentando sobre o lugar do copista na Idade Média e que, a nosso ver, podemos trazer para atualidade, nos ensina: "a língua ilude e pega em sua armadilha o copista que ela institui como sujeito"18, visto que, ao produzir sua leitura sobre o arquivo e ou sobre o corpus saussuriano, acabamos por nos fazer lembrar daquilo que, já cimentado, possa formar mais uma camada na imensidão do que é produzir conhecimento sobre a língua.

\title{
À GUISA DE CONCLUSÃo OU O FIM DO PASSEIO GUIADO (MAS NÃO DA BIBLIOTECA)
}

\begin{abstract}
"Atrevo-me a insinuar esta solução do antigo problema: A Biblioteca é ilimitada e periódica. Se um eterno viajante a atravessasse em qualquer direção, comprovaria ao fim dos séculos que os mesmos volumes se repetem na mesma desordem (que, reiterada, seria uma ordem: a Ordem). Minha solidão alegra-se com essa elegante esperança" (BORGES, 1941, p. 39).
\end{abstract}

O leitor que nos acompanha até aqui deve estar se perguntando: os manuscritos saussurianos serão guardados em qual galeria? Aqui convidamos o leitor para voltar ao mundo real e lembrar que tais manuscritos estão guardados, em sua maior parte, na Biblioteca de Genebra (Suiça) e também em Houghton Library, de Harvard (Estados Unidos). O acesso a esses manuscritos, hoje, é mediado por um trabalho cuidadoso e minucioso de pesquisadores que se dedicam a montar e decifrar um conjunto de notas na tentativa de atribuir uma ordem. De Mauro (2016, p. 37, tradução nossa) atribui a esse trabalho pesaroso um ar poético:

Certamente, estes materiais estão em desordem. A atmosfera geral que se desprende parece aquela de um ateliê onde trabalha o artista: dispersão de fragmentos, de cacos, de resíduos, de esboços; entretanto, aqui e acolá, alguma coisa de mais acabado aparece e, às vezes, admiravelmente acabado: trata-se, em resumo, de uma desordem à procura de uma invenção de uma ordem nova ${ }^{19}$.

O que significa reconhecer que, para acessar esses manuscritos, será necessário inventar uma (nova) ordem, e essa ordem, por sua vez, sempre poderá ser outra, uma vez que o autor dos manuscritos já não pode mais nos dizer qual seria a sua escolha. É muito provável que Saussure também não soubesse que ordem dar, pois, em várias notas, ele faz alusão à dificuldade de começar e dar

18 "la langue miroite et prend dans son piège le copiste qu'elle institue en sujet".

19 "Bien entendu, ces matériaux sont en désordre. L'atmosphère générale qui s'en dnégage ressemble à celle d'un atelier où travaille l'artiste: parsemé de fragments, de débris, de déchets, d'ébauches; cependant, ici et là, quelque chose de plus fini apparaît, et parfois même, d'admirablement fini: il s'agit en somme d'un désordre à la recherche de l'invention d'un ordre nouveau." 
linearidade a sua reflexão, dada a complexidade da natureza do objeto de estudo. Segundo De Mauro (2016, p. 37, tradução nossa),

O próprio Saussure toma posição sobre o problema da ordem e (diremos à maneira de Croce, tradutor de Hegel) "del cominciamento". É uma questão que o atormenta, como atormentou já Pascal e Hegel e igualmente o último Wittgenstein com suas Investigações filosóficas ${ }^{20}$.

Defendemos (SCHERER; COSTA, 2019), inclusive, que o corpus saussuriano constitui-se enquanto um livro de areia, no sentido poético e metafórico atribuído por Borges, considerando que a ordem em que os manuscritos encontram-se, seja no Fundo Documental ou nas edições publicadas, sempre nos escapa por entre os dedos, seja pela ordem atribuída pelos editores, seja pela ordem atribuída pelo autor dos manuscritos. Essa dificuldade permite-nos imaginar uma ordem possível e também nos impõe a necessidade de refletir que poderia ser de outra forma, tal como um livro de areia, que poderia ganhar diferentes formas e tornar-se outro: do mesmo modo que essa biblioteca continua sempre em aberto. A partir desse livro de areia que constitui as tantas versões que conhecemos do CLG, podemos esperar também uma Biblioteca de Babel à la Borges desse conjunto de textos saussurianos? Em nosso entender, todos os textos que já foram publicados (e os que virão a ser) na busca de tentar compreender essa problemática, inclusive o presente texto, somam-se a essa biblioteca de Babel saussuriana que se abre para uma promessa de um possivel infinito, pois, para nós,

Tudo está ordenado no mundo e é isso que causa um medo extremo ao homem. Nada de mais aterrorizante do que essa glória do real não feita para nossos olhos. O que dá um medo extremo não é o caos daqui, nem as coisas em labirinto, mas a arrumação absoluta de tudo e a súbita aparição do universo numa língua ordenada. Não é o amontoado, o inominável da matéria que dá medo, mas ouvir uma ordem ali dentro. Não é uma coisa que se compreende pela visão - já que tudo é desordem para se ver - mas uma coisa que se ouve. Ouvimos uma ordem na linguagem. E ouvimos uma ordem no tempo (NOVARINA, 2009, p. 23).

\section{SAUSSURIAN LIBRARY ì LA BORGES: AN INVITATION}

Abstract: Reflect on the work of Ferdinand de Saussure implies referring to the problem of notions of corpus and archive in what concerns about the heterogeneous set of publications that were published by Saussure and attributed to him. Starting from this problematic and inspired by a Borges short story, "A Biblioteca de Babel", in this article, we seek to propose a reflection on the permanence of the Course in General Linguistics and its inconstancy, as well as on its capacity to be reinvented and to maintain itself present for more than a century. We will also reflect on the hard work of researchers who have been dedicated to the study of this complex heterogeneous set of texts to which is attributed to Saussure. In the style of a library (like Babel à la Borges), we or-

20 "Saussure lui-même prend position sur le problème de l'ordre et (dirons nous à la manière de Croce, traducteur de Hegel) 'del cominciamento'. C'est là une question qui le tourmente, comme elle a tourmenté déjà Pascal et Hegel et également le dernier Wittgenstein aux prises avec ses Investigations philosophiques." 
ganized our text by shelves (of hexagonal galleries) to try to understand the vastness and complexity of the set of works and documents attributed to Saussure.

Keywords: History. Memory. Corpus. Archive. Manuscripts.

\section{REFERÊNCLAS}

AUROUX, S. (dir.). Histoire des idées linguistiques. Bruxelles: Pierre Mardaga, 1989. t. 1.

AUROUX, S. A questão da origem das linguas seguido de A historicidade das ciências. Tradução Mariângela Joanilho. Campinas: Editora RG, 2008.

BACHELARD, G. Epistemologia. Tradução Nathanael C. Caixeiro. 2. ed. Rio de Janeiro: Zahar Editores, 1983.

BENVENISTE, É. Lettres de Ferdinand de Saussure à Antoine Meillet. Cahiers Ferdinand de Saussure, n. 21, p. 89-135, 1964. Disponivel em: https://www. cercleferdinanddesaussure.org/CFS/Volume_21_1964.pdf. Acesso em: 22 jul. 2020.

BORGES, J. L. A biblioteca de Babel. In: BORGES, J. L. Ficções. Lisboa: Livros do Brasil, 1941. Disponivel em: https://edisciplinas.usp.br/pluginfile.php/5151 626/mod_resource/content/0/BORGES_Fic\%C3\%A7\%C3\%B5es.pdf. Acesso em: 11 ago. 2020.

BOUQUET, S. Principes d'une linguistique de l'interprétation: une épistémologie néosaussurienne. Langages, n. 185, p. 21-33, 2012. Disponivel em: https:// www.cairn.info/revue-langages-2012-1-page-21.htm. Acesso em: 3 jun. 2020.

CERQUIGLINI, B. Eloge de la variante: histoire critique de la philologie. Paris: Du Seuil, 1989.

CHISS, J.-L.; PUECH, C. Fondations de la linguistique, études d'histoire et d'épistémologie. Bruxelles: De Boeck, 1987.

COSTA, M. I. S. A definição atribuída à designação "sintagma": deslocamento e efeitos de sentido. 2012. Dissertação (Mestrado em Linguística) - Universidade Federal de Santa Maria, Santa Maria, 2012.

COSTA, M. I. S. A produção do conhecimento sobre a lingua na segunda metade do século XX no Brasil: o funcionamento da contradição no discurso do gramático. 2015. Tese (Doutorado em Linguística) - Universidade Federal de Santa Maria, Santa Maria, 2015.

COURTINE, J.-J. O tecido da memória: algumas perspectivas de trabalho histórico nas ciências da linguagem. Tradução Roberto Leiser Baronas e Nilton Milanez. Polifonia, Cuiabá, v. 12, n. 2, p. 1-13, 2006. Disponivel em: http:// www.periodicoscientificos.ufmt.br/ojs/index.php/polifonia/article/viewFile/ 10 67 /840?fbclid=IwAR1 pyUIJ7V7aDDFSJpz4pIZK8FCqcARcJ9Bor_2c3wPw6sYP OXX79Sew004. Acesso em: 29 abr. 2020.

DE MAURO, T. F. De Saussure, Écrits de Linguistique Générale, Introduction. In: RASTIER, F. (org.). De l'essence double du langage et le renouveau du saussurisme. Paris: Lambert-Lucas, 2016. 
DE MAURO, T. ... Tradução Amanda Scherer e Maria Iraci Sousa Costa. Fragmentum, Santa Maria, n. esp., p. 239-257, 2018. Disponivel em: https:// periodicos.ufsm.br/fragmentum/article/view/36595/19845. Acesso em: 29 abr. 2020.

DESCENDRE, R. A "descoberta": a história de uma invenção semântica (primeiros elementos). Tradução José Horta Nunes. Revista Línguas e Instrumentos Linguisticos, Campinas, n. 35, p. 11-28, 2015. Disponível em: http://www. revistalinguas.com/edicao35/artigo1.pdf. Acesso em: 29 abr. 2020.

FENOGLIO, I. Manuscritos de linguistas e genética textual: quais os desafios para as ciências da linguagem? Exemplos através dos "papiers" de Benveniste. Tradução Simone de Mello de Oliveira, Verli Petri e Zélia Maria Viana Paim. Santa Maria: PPGL-Editores, 2013.

FIORIN, J. L.; FLORES, V. do N.; BARBISAN, L. B. (org.). Saussure: a invenção da linguística. São Paulo: Contexto, 2013.

FLORES, V. do N. Saussure e Benveniste no Brasil: quatro aulas na École Normale Supérieure. São Paulo: Parábola, 2017.

KYHENG, R. Principes méthodologiques de constitution et d'exploitation du corpus saussurien. Texto!, v. XII, n. 2, avr. 2007. Disponivel em: http://www. revue-texto.net/1996-2007/Saussure/Sur_Saussure/Kyheng/Kyheng_Corpussaussurien.html. Acesso em: 29 fev. 2020.

LACAN, J. Le séminaire livre XXIII, le sinthome. Paris: Éditions du Seuil, 2005. MATTOSO CÂMARA JR., J. A linguística brasileira. In: NARO, A. J. (org.). Tendências atuais da linguistica e da filologia no Brasil. Tradução Maria Candida Diaz Bordenave e Marilda Winkler Averbug. Rio de Janeiro: Francisco Alves, 1976.

NORMAND, C. Saussure. Tradução Ana de Alencar e Marcelo Diniz. São Paulo: Estação Liberdade, 2009.

NOVARINA, V. Diante da palavra. Tradução Angela Leite Lopes. 2. ed. Rio de Janeiro: 7Letras, 2009.

PAVEL, T. A miragem linguistica: ensaio sobre a modernização intelectual. São Paulo: Pontes, 1990.

PUECH, C. L'esprit de Saussure: réception et héritage (1'héritage linguistique saussurien: Paris contre Genève). Les dossiers de HEL [supplément électronique à la revue Histoire Épistémologie Langage], Paris, SHESL, n. 3, 2013. Disponivel em: http://htl.linguist.univ-paris-diderot.fr/num3/puech.pdf. Acesso em: 29 abr. 2020.

ROUSSET, J. Forme e signification. Paris: José Conti, 1964.

SALUM, I. N. Prefácio à edição brasileira. In: SAUSSURE, F. de. Curso de Linguistica Geral. Organizado e editado por Charles Bally e Albert Sechehaye. Tradução Antônio Chelini, José Paulo Paes e Izidoro Blikstein. 27. ed. São Paulo: Cultrix, 2006. p. XIII-XXIII.

SAUSSURE, F. de. Notes inédites de F. de Saussure (éditées par Robert Godel). Revue Cahiers Ferdinand de Saussure, v. 12, p. 49-71, 1954. Disponivel em: http://www.cerclefdsaussure.org/download/cfs_pdf/Volume_12_1954.pdf. Acesso em: 10 set. 2018.

SAUSSURE, F. de. Cours de Linguistique Générale. Édition critique preparée par Tullio De Mauro. Paris: Payot, 1974. 
SAUSSURE, F. de. Écrits de Linguistique Générale. Organisés et édités par Simon Bouquet et Rudolf Engler. Paris: Gallimard, 2002.

SAUSSURE, F. de. Curso de Linguística Geral. Organizado e editado por Charles Bally e Albert Sechehaye. Tradução Antônio Chelini, José Paulo Paes e Izidoro Blikstein. 27. ed. São Paulo: Cultrix, 2006.

SAUSSURE, F. de. Science du langage - de la double essence du langage. Édition des écrits de linguistique générale établie par René Amacker. Genève: Librarie Droz, 2011.

SAUSSURE, F. de. Anagrammes homériques. Éditées par Pierre-Yves Testenoire. Limoges: Éditions Lambert-Lucas, 2013. 445 p.

SAUSSURE, F. de. Une vie en lettres (1866-1913). Diachronie dressée par Claudia Mejía Quijano. Nantes: Éditions Nouvelles Cécille Defaut, 2014.

SAUSSURE, F. de. La "collation Sechehaye" du "Cours de Linguistique Générale" de Ferdinand de Saussure. Édition, introduction et notes par Estanislao Sofia. Leuven, Paris, Bristol: Peeters, 2015.

SCHERER, A. E.; COSTA, M. I. S. Ainda (e sempre) Saussure: história, memória e discurso em três versões de um mesmo texto. Letrônica, Porto Alegre, v. 11, n. supl., p. 54-67, set. 2018. Disponivel em: http://revistaseletronicas.pucrs.br/ ojs/index.php/letronica/article/view/30804/17313. Acesso em: 29 fev. 2020.

SCHERER, A. E.; COSTA, M. I. S. A problemática acerca da edição das notas saussurianas: um livro sem fim nem começo ou um livro de areia à la Borges? Leitura (Novo retorno a Saussure), Maceió, v. 1, n. 62, p. 191-214, jan./jun. 2019. Disponivel em: http://www.seer.ufal.br/index.php/revistaleitura/article/ viewFile/4944/4527. Acesso em: 29 fev. 2020.

SCHNEIDERS, C. M. Serafim da Silva Neto: entre a constituição e a circulação do conhecimento linguístico. 2014. Tese (Doutorado em Linguística) - Universidade Federal de Santa Maria, Santa Maria, 2014.

SÉRIOT, P. Limites, bordas e normas: a delicada constituição do objeto de conhecimento nas ciências humanas. Tradução Amanda Eloina Scherer e Maria Iraci Sousa Costa. Organon, Porto Alegre, v. 30, n. 59, p. 55-70, 2015. Disponível em: https://seer.ufrgs.br/organon/article/view/57195/35599. Acesso em: 29 abr. 2020.

SOFIA, E. Quelques problèmes philologiques posés par l'œuvre de Ferdinand de Saussure. Langages, n. 185, p. 35-50, 2012. Disponivel em: https://www. cairn.info/revue-langages-2012-1-page-35.htm. Acesso em: 10 mar. 2020.

SOFIA, E. Qui est l'auteur du Cours de linguistique générale? Recherches sémiotiques/Semiotic Inquiry, v. 34, n. 1-2-3, p. 39-57, 2014. DOI 10.7202/1037145ar. Disponivel em: https://www.erudit.org/en/journals/rssi/2014-v34-n1-2-3rssi02602/1037145ar/. Acesso em: 29 fev. 2020.

SOUZA, M. de O. Os anagramas de Saussure: entre a poesia e a teoria. 2012. Dissertação (Mestrado em Linguística) - Universidade Federal de Uberlândia, Uberlândia, 2012.

SOUZA, M. de O. Os anagramas de Saussure: um percurso pelo lado pitoresco das linguas. 2017. Tese (Doutorado em Linguística) - Universidade Federal de Uberlândia, Uberlândia, 2017. 
SOUZA, M. de O. Os anagramas de Saussure: entre a poesia e a teoria. Uberlândia: Editora da Universidade Federal de Uberlândia, 2018.

STAROBINSKI, J. As palavras sob as palavras: os anagramas de Saussure. Tradução Carlos Vogt. São Paulo: Perspectiva, 1974.

STAROBINSKI, J. La matière des idées: dialogue avec Serge Zenkine. Bulletin 4, Cercle d'études internationales Jean Starobinski, Édité par les Archives littéraires suisses, p. 1-24, 2011. Disponivel em: https://www.nb.admin.ch/snl/fr/home/ portrait/als / publications / bulletin-du-cercle-d-etudes-internationales-jeanstarobinski/bulletin-starobinski-bisher.html. Acesso em: $1^{\circ}$ jun. 2020.

TESTENOIRE, P.-Y. Ferdinand de Saussure, à la recherche des anagrammes. Limoges: Éditions Lambert-Lucas, 2013. 349 p.

TRABANT, J. O Curso em busca de autor. Tradução Márcio Alexandre Cruz. Leitura (Novo retorno a Saussure), Maceió, v. 1, n. 62, p. 381-393, jan./jun. 2019. Disponivel em: http://www.seer.ufal.br/index.php/revistaleitura/article/ view/5460/4519. Acesso em: 29 fev. 2020. 